\title{
Epigenetic changes in colorectal cancer
}

\author{
Yan $\mathrm{Jia}^{1,2}$ and Mingzhou Guo ${ }^{1}$
}

\begin{abstract}
Epigenetic changes frequently occur in human colorectal cancer. Genomic global hypomethylation, gene promoter region hypermethylation, histone modifications, and alteration of miRNA patterns are major epigenetic changes in colorectal cancer. Loss of imprinting (LOI) is associated with colorectal neoplasia. Folate deficiency may cause colorectal carcinogenesis by inducing gene-specific hypermethylation and genomic global hypomethylation. HDAC inhibitors and demethylating agents have been approved by the FDA for myelodysplastic syndrome and leukemia treatment. Non-coding RNA is regarded as another kind of epigenetic marker in colorectal cancer. This review is mainly focused on DNA methylation, histone modification, and microRNA changes in colorectal cancer.
\end{abstract}

Key words: DNA methylation, histone modification, microRNA (miRNA), epigenetics, colorectal cancer (CRC), field defect

Colorectal cancer (CRC) is the second most common malignant disease in developed countries, with 1 million new cases and 500000 deaths worldwide every year ${ }^{[1]}$, and it is the third leading cause of cancer-related death in both men and woman in industrialized countries ${ }^{[2]}$. The accumulation of gene mutations and epigenetic alterations may drive the initiation and progression of benign adenoma to malignant adenocarcinoma ${ }^{[3,4]}$.

Epigenetics is defined as inheritable changes in gene expression without DNA sequence changes. The field of epigenetics includes DNA methylation, histone modification and non-coding RNAs. Increasing evidence shows that aberrant epigenetic changes play important roles in human cancer. Numerous DNA methylation and microRNA (miRNA) patterns have been regarded as tumor markers. Because of the reversible nature of epigenetic alterations, epigenetic associated agents are being developed ${ }^{[5,6]}$. In this review, we mainly focus on changes of DNA methylation, histone modification and miRNAs in colorectal cancer, especially on the potential clinical applications.

\footnotetext{
Authors' Affiliations: 'Department of Gastroenterology \& Hepatology, Chinese PLA General Hospital, Beijing 100853, P. R. China; ${ }^{2}$ Medical College of Nankai University, Tianjin 300071, P. R. China.

Corresponding Author: Mingzhou Guo, Department of Gastroenterology \& Hepatology, Chinese PLA General Hospital, \#28 Fuxing Road, Beijing 100853, P. R. China. Tel: +86-10-66937651; Fax: +86-10-68180325; Email: mzguo1@gmail.com.

doi: 10.5732/cjc.011.10245
}

\section{DNA Methylation}

DNA methylation is a normal procedure to maintain gene expression with normal patterns in mammalian cells. It is involved in the regulation of gene imprinting, $\mathrm{X}$-chromosome inactivation and other biological activities $^{[7,8]}$. Methylation of cytosine on DNA is well studied in epigenetics. CpG-rich regions constituted by CpG dinucleotides are known as $\mathrm{CpG}$ islands ${ }^{[9]}$. CpG islands in the gene promoter region are usually unmethylated, and the sporadic $\mathrm{CpG}$ sites in the gene body are normally methylated. However, during aging or carcinogenesis, the pattern will become global hypomethylation and promoter region hypermethylation ${ }^{[10,11]}$.

The proteins involved in epigenetic regulation are DNA methyltransferase (DNMT), methyl-CpG-binding protein (MBP), histone deacetylase (HDAC), histone acetylase (HAT), and histone methyltransferase (HMT) ${ }^{[12-14]}$. DNMT3A and $3 \mathrm{~B}$ are de novo methyltransferases that function mainly to establish methylation patterns, whereas DNMT1 is a methyltransferase that maintains methylation patterns. Hence, these enzymes cooperate to regulate cellular DNA methylation patterns ${ }^{[11,15]}$. The other DNMTs are DNMT3L and DNMT2. DNMT3L is reported to be required for the methylation of imprinted genes in germ cells and has been found to interact with DNMT3a and $3 b$ in de novo methyltransferase activity. Although the biological function of DNMT2 remains unclear, its strong binding to DNA suggests that it may 
target specific sequences in the genome ${ }^{[16,17]}$. Methyl-CpG binding proteins (MBPs), including methyl-CpG binding protein 2 (MeCP2) and methyl-CpG binding domains (MBD1, MBD2, MBD3, and MBD4), may block transcription factor binding to DNA by recruiting chromatin remodeling corepressor complexes ${ }^{[18,19]}$. HATs, HDACs and HMTs are mainly responsible for histone modification and chromatin remodeling ${ }^{[20,21]}$.

\section{DNA hypermethylation in CRC}

Promoter region hypermethylation is found in a variety of cancers. Many of the affected genes are involved in cell cycle regulation, DNA repair, apoptosis, angiogenesis, invasion, and adhesion. The methylation profile varies in different types of cancer, but similar DNA methylation patterns were found in sporadic and inherited colon cancers ${ }^{[2]}$.

Effective approaches are needed to screen premalignant adenomas and early stage cancers to reduce mortality of $\mathrm{CRC}$. Epigenetic silencing of numerous tumor suppressor genes by promoter region hypermethylation has been found in a variety of cancers, including $\mathrm{CRC}^{[23,24]}$. Epigenetic changes were frequently found in precancerous lesions and adjacent tissues of CRC ${ }^{[25-28]}$. Growth-regulatory genes have been found to be epigenetically silenced in colonic mucosa in elder individuals, which may increase risk of cancer associated with aging ${ }^{[29]}$. Methylation of ASC/TMS1 was reported to be a late-stage event in $\mathrm{CRC}^{[30]}$, whereas hypermethylation of SOX17 is an early event of CRC ${ }^{[31]}$. Methylation of hMLH1, p16, DAP-kinase, APC, MGMT, RASSF2A, and Wif-1 were regarded as plasma or serum detection markers ${ }^{[32-36]}$. DNA methylation may serve as diagnostic, therapeutic, or prognostic markers for CRC (Table 1).

\section{CpG island methylator phenotype in CRC}

Cancer classification was mainly based on microscopic morphology and immunohistochemistry. Molecular classification was recognized as an important tool in clinic. Some molecular markers have been applied for cancer prevention, prognosis and chemosensitivity. Gefitinib-sensitizing mutation is one of the examples.

Fearon et al. ${ }^{[37]}$ suggested in 1990 that most CRCs arise from adenoma and that multiple gene mutations were accumulated during carcinogenesis. One group of

Table 1. Clinical value of methylated genes in colorectal cancer

\begin{tabular}{|c|c|c|c|c|c|}
\hline Gene & Authors & Year & Clinical value & Follow-up & Reference \\
\hline $\begin{array}{l}\text { CDH13/ } \\
\text { FLBN3 }\end{array}$ & Wang Z, et al. & 2011 & Poor prognosis & $\begin{array}{l}\text { Median duration is } 44 \text { months } \\
\text { (range, 3-60 months) }\end{array}$ & [114] \\
\hline$p 16^{\text {INKAa }}$ & Mitomi $\mathrm{H}$, et al. & 2010 & Larger size of tumor, frequent recurrence and poor prognosis & $\begin{array}{l}\text { Median duration is } 79 \text { months } \\
\text { (range, } 60-123 \text { months) }\end{array}$ & [115] \\
\hline PPARG & Pancione $\mathrm{M}$, et al. & 2010 & Poor prognosis & $\begin{array}{l}\text { Average post-operative duration } \\
\text { is } 59.56 \pm 26.5 \text { months }\end{array}$ & [116] \\
\hline EphA1 & Herath $\mathrm{NI}$, et al. & 2009 & Poor prognosis & Two years & [117] \\
\hline DKK1 & Rawson JB, et al. & 2011 & Related to MSI tumors; indicates favorable outcome & NA & [118] \\
\hline SFRP1 & Rawson JB, et al. & 2011 & Associated with MSI tumors inversely; indicates poor outcome & NA & [118] \\
\hline GALR2 & Kim JC, et al. & 2011 & Chemosensitive methylation candidates to bevacizumab & NA & [119] \\
\hline$A L X 4$ & Kim JC, et al. & 2011 & Chemosensitive methylation candidates to cetuximab & NA & [119] \\
\hline$E R$ & Harder J, et al. & 2009 & High risk for local recurrence & NA & [120] \\
\hline CHFR & Brandes JC, et al. & 2005 & Correlates with the microsatellite instability phenotype & NA & [121] \\
\hline OSMR & Kim MS, et al. & 2009 & Highly specific diagnostic biomarker in fecal DNA & NA & [122] \\
\hline SFRP2 & Huang Z, et al. & 2007 & Detection of $\mathrm{CRC}$ and precancerous lesions in stool DNA & NA & [123] \\
\hline SFRP2 & Oberwalder $\mathrm{M}$, et al. & 2007 & Detection of precancerous lesions of CRC in stool DNA & NA & [124] \\
\hline DAPK & Mittag $\mathrm{F}$, et al. & 2006 & Early event in CRC carcinogenesis & NA & [125] \\
\hline TFPI2 & Glockner SC, et al. & 2009 & Potential detection marker in stool DNA & NA & [126] \\
\hline GATA4 & Hellebrekers DM, et al. & 2009 & Potential detection marker in stool DNA & NA & [127] \\
\hline GATA5 & Hellebrekers DM, et al. & 2009 & Potential marker & NA & [127] \\
\hline NGX6 & Liu $\mathrm{M}$, et al. & 2010 & Potential marker & NA & [128] \\
\hline $\mathrm{CDH} 4$ & Miotto $\mathrm{E}$, et al. & 2004 & Potential marker & NA & [129] \\
\hline Sox17 & Zhang W, et al. & 2008 & Potential marker & NA & [31] \\
\hline$p 15^{1 K K 4 b}$ & Ishiguro $\mathrm{A}$, et al. & 2006 & Potential marker & NA & [130] \\
\hline
\end{tabular}


CRC is characterized by high level DNA microsatellite instability (MSI-H), CpG island methylator phenotypehigh (CIMP-high), and BRAF mutation. This type of cancer, which predominantly affects females and usually occurs in the proximal colon, arises in serrated polyps and not in adenomas ${ }^{[38-40]}$. The existence of CIMP was initially suggested by Toyota et al. ${ }^{[24]}$, who reported that CRC fell into two categories: one group that shows rare methylation (CIMP-negative) and another group that shows aberrant methylation of several genes simultaneously (CIMP-positive). The five "classic" CIMP markers, CDKN2A, MINT1, MINT2, MINT3, and MLH1, provide a simplified and representative approach in defining CIMP ${ }^{24,41]}$. The mechanism underlying CIMP tumor development is unknown, however, it is known that sporadic CRC can be divided according to their degree of methylation of CIMP markers. It appears that cancers with high degrees of methylation (CIMP) represent a clinically and etiologically distinct group, one constituting "epigenetic instability," and seem to have distinct epidemiological, histological, and molecular features $^{[40]}$.

\section{DNA hypomethylation, field defect, and LOI in CRC}

Global DNA hypomethylation in human colonic cancer was first reported by Feinberg et al. ${ }^{[42]}$ in 1983. Recently, hypomethylation of $\mathrm{CDH} 3$ (P-cadherin) promoter was found in aberrant crypt foci (ACF) and CRC, with a potential field defect of $\mathrm{CDH} 3$ hypomethylation in the adjacent epithelium of cancer. In another study, a significant association was found between aberrant demethylation of $\mathrm{CDH} 3$ and tumor site or Dukes stage. Promoter region hypomethylation is associated with induction of $\mathrm{CDH} 3$ expression in $\mathrm{CRC}^{[43]}$.

The term field defect was used to describe the accumulation of genetic and epigenetic alterations in tissues with normal appearance ${ }^{[44]}$. Promoter region hypermethylation was considered an evaluation marker for field defect in lung and colonic cancer. The discovery of field defect markers could be of great use in mucosa that appears normal, both for early detection and risk assessment for colon cancer (such as MGMT promoter methylation in $\mathrm{CRC})^{[25,45]}$.

Genomic imprinting is an epigenetic modification of a specific parental chromosome in the gamete or zygote, leading to parental, origin-specific, differential expression of the two alleles of a gene in somatic cells of the offspring. In 1993, Rainier et al. ${ }^{[46]}$ and Ogawa et al. ${ }^{[47]}$ simultaneously reported loss of imprinting (LOI) of IGF2 in Wilms tumor, and later, similar observations were made in many other malignancies, including $\mathrm{CRC}^{[48,49]}$. Cui et al. ${ }^{[48]}$ analyzed LOI in 172 patients under colonoscopy and found a 4.7-fold increased likelihood of LOI among patients with CRC (past or present) and a 5.2-fold increased likelihood of LOI among patients with a positive family history of CRC among first-degree relatives. $\mathrm{LOI}$ is found in normal colonic mucosa of about $30 \%$ of CRC patients, but it is found in only $10 \%$ of healthy individuals. These results indicate that LOI, which can be assayed with a DNA-based blood test, may be a valuable predictive marker of an individual's risk for $\mathrm{CRC}^{[50]}$.

\section{The effect of diet on DNA methylation in CRC}

Diet and lifestyle play important roles in cancer biology. Inappropriate diet may contribute to one third of cancer deaths ${ }^{[51]}$. Alcohol decreases folate absorption, alters its metabolism, increases its excretion, and therefore may interfere with both DNA methylation and thymidylate synthesis ${ }^{[52-54]}$. Several studies show an association between high alcohol intake and CRC, which suggests that the carcinogenic effect of alcohol in the colon is mediated through its adverse effect on folate status ${ }^{[5,56]}$. A few reports suggest that people who habitually consume high level of folate have a significantly reduced risk of developing colon polyps or cancer ${ }^{[57,58]}$. Folate maintains genomic stability by regulating DNA biosynthesis, repair and methylation (Figure 1). Folate deficiency may induce gene-specific DNA hypermethylation and global DNA hypomethylation ${ }^{[59]}$. The impact of certain micronutrients on DNA methylation adds to our current understanding of possible mechanisms linking diet to CRC.

\section{Histone Modifications}

Histone modifications, such as phosphorylation, acetylation, or methylation, in localized promoter regions are histone codes for chromatin packing and transcription ${ }^{[60]}$. In general, methylation of $\mathrm{H} 3 \mathrm{~K} 4, \mathrm{H} 3 \mathrm{~K} 36$, and $\mathrm{H} 3 \mathrm{~K} 79$ are linked to gene expression activation, whereas H3K9me2, H3K9me3, H3K27me3 and H4K20 are associated with gene repression ${ }^{[61-64]}$. The global pattern of histone modifications has been considered a predictor for the risk of recurrence of human cancers ${ }^{[65,66]}$. Histone acetyltransferases (HATs) and deacetylases (HDACs) are responsible for the addition and removal of acetyl groups from lysine residues. In cancer cells, disruption of the balance between HATs and HDACs contributes to transcriptional inactivation of tumor suppressor genes (TSGs). Cyclin-dependent kinase inhibitor p21W/F-1 is repressed by promoter hypoacetylation in the absence of CpG island hypermethylation, and expression can be reactivated by inhibition of HDAC activity ${ }^{[67]}$. Interestingly, some TSGs with CpG island hypermethylation can also be re-expressed through inhibition of SIRT1, a class III HDAC that increases $\mathrm{H} 4 \mathrm{~K} 16$ and $\mathrm{H} 3 \mathrm{~K} 9$ acetylation at promoters, without affecting the hypermethylation status ${ }^{[68]}$. 


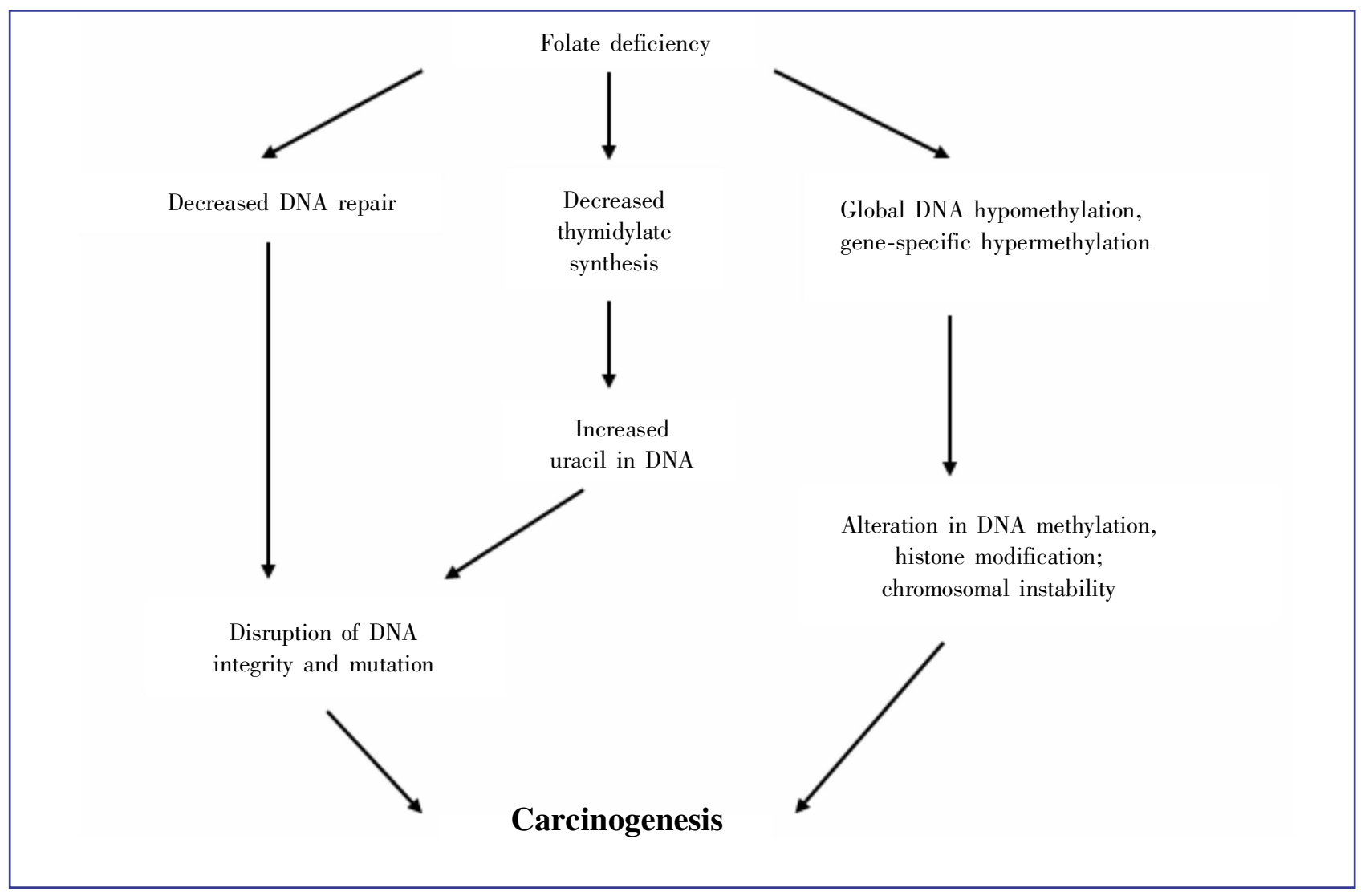

Figure 1. Folate and regulation of DNA synthesis, repair, and methylation. Folate deficiency may decrease thymidylate syntheses, inhibit DNA repair, induce imbalance of DNA methylation, histone modification, and finally cause carcinogenesis.

Similar to histone acetylation, histone methylation is dynamically regulated by both histone methyltransferases (HMTs) and histone lysine demethylases (HDMTs). Methylation takes place on both lysine and arginine residues and has different degrees, including mono-, di-, and trimethylation. H3K27-specific HMT (enhancer of zeste homolog 2, EZH2), catalytic subunit of polycomb-repressive complex 2 (PRC2), is overexpressed in human cancers, including colon cancer ${ }^{[69]}$. H3K27me3 is also regulated by RAS signaling pathway and further affects cyclin D1 and E-cadherin expression. Overexpression of oncogenic RAS influences global and gene-specific histone modification during the epithelialmesenchymal transition (EMT) in Caco-2 CRC cells ${ }^{[70]}$.

DNA methylation-mediated gene silencing is closely linked to histone deacetylation ${ }^{[71,72]}$. Histone methylation at key lysine residues has been shown to work in concert with acetylation and other modifications to provide a histone code that may determine heritable transcriptional states ${ }^{[73]}$. In lower eukaryotes, methylated H3K9 determines DNA methylation and correlates with transcription repression $^{[74,75]}$ (Figure 2). DNA methylation maintains key repressive elements of the histone code at a hypermethylated gene promoter in RKO colon cancer cells. $h M L H 1$, a mismatch repair gene, is often silenced by aberrant $\mathrm{CpG}$ island hypermethylation in colorectal cancers $^{[6]}$. Deacetylated histone $\mathrm{H} 3$ (deacetylated histone $\mathrm{H} 3 \mathrm{~K} 9$ and $\mathrm{H} 3 \mathrm{~K} 14$ ) plus methyl-H3-K9 surround the hypermethylated and inactive $h M L H 1$ promoter, whereas unmethylated and active $h M L H 1$ promoter is embedded in methyl-H3-K4 and acetylated $\mathrm{H} 3$ (acetylated histone H3K9 and H3K14). Promoter demethylation, gene reexpression, and finally complete histone code reversal were induced only by inhibiting DNA methyltransferases, not HDAC ${ }^{[77]}$

\section{HDACs, HDAC Inhibitors, and Demethylating Agents}

Alterations in HDACs are found in many human cancers including $\mathrm{CRC}{ }^{[14,78]}$. The expression of HDAC1, HDAC2, HDAC3, and HDAC8 are reported to be increased in colon cancer ${ }^{[78-80]}$. Retinoblastoma $(\mathrm{Rb})$ is a 


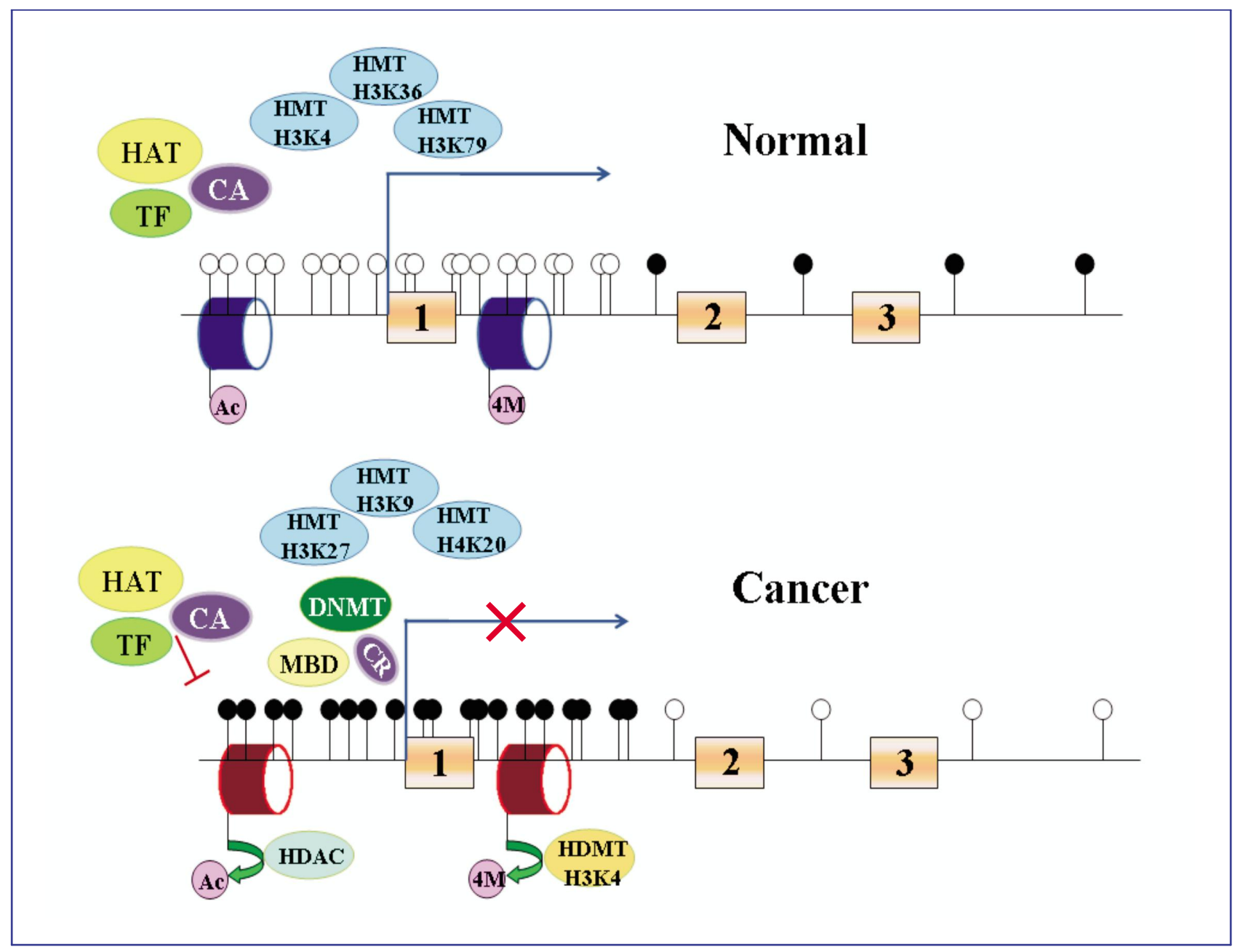

Figure 2. Eplgenetlc regulation of gene expresslon. Promoter region of tumor suppressor gene is unmethylated in normal cells and methylated in cancer cells. Filled cycles represent methylated DNA; unfilled cycles represent unmethylated DNA. Blue cylinder represents active histone modification; red cylinder represents repressive histone modification. 1, 2 and 3 represent exons 1, 2 and 3. HMT, histone methyltransferase; HAT, histone acetylase; DNMT, DNA methyltransferase; MBP, methyl-CpG binding protein; HDAC, histone deacetylase; TF, transcription factors; CA, co-activator; CR, co-repressor; Ac, acetylation; 4M, H3K4 methylation.

tumor suppressor that represses gene expression by modulating the architecture of chromatin. $\mathrm{Rb}$ recruits HDAC to E2F and cooperates with HDAC1 to repress E2F-regulated promoter of genes encoding cell cycle protein cyclin $E{ }^{[81,82]}$. HDAC1 facilitates the removal of highly charged acetyl groups from core histones, causing a tighter association between DNA and nucleosomes and preventing transcription factor from accessing to DNA. This repression is released when, on exposure to proliferative signals, G1 cyclin dependent kinases phosphorylate $\mathrm{Rb}^{[83]}$. Histone deacetylase inhibitors (HDACi), such as short chain fatty acid and butyrate, have been recognized and utilized to induce growth arrest, differentiation, and apoptosis for several decades ${ }^{[84,85]}$. Trichostatin A (TSA) was the first natural hydroxamate discovered to inhibit HDACs. Vorinostat (SAHA) is structurally similar to TSA and the first HDACi to be approved for clinical application ${ }^{[86,87]}$. A number of dietary factors with HDAC inhibitory activity and antitumor effects in the colon have been described ${ }^{[85,88]}$. To date, several clinical trials of HDACi have shown a preferential clinical efficacy. Elucidation the mechanism of $\mathrm{HDACi}$ may help to develop more effective therapeutic drugs ${ }^{[89]}$. HDACi are also potent sensitizers of radiation therapy in multiple cell types, including colon cancer cells.

DNA methylation is reversible under certain circumstances. It is possible to induce reexpression of silenced genes by demethylating agents in cancer cell lines. Two such agents, 5-azacytidine (Vidaza) and 5-aza-2' deoxycytidine (decitabine), have been approved for both myelodysplastic syndrome and leukemia ${ }^{[00,91]}$. 


\section{MicroRNAs in Colorectal Carcinogenesis}

MicroRNA (miRNA) is a kind of non-coding RNA and the length is about 18-22 nucleotide. The major role of miRNA is regulation of gene expression ${ }^{[92-94]}$. miRNAs have been found to play an important role in cancer initiation and progression ${ }^{[05]}$. Furthermore, the patterns of miRNAs expression were considered diagnostic, prognostic, and chemosensitivity markers in various types of cancer.

Loss of miR-133a and gain of miR-224 are associated with CRC tumorigenesis. Reduced expression of miR-143 and miR-145 were found in CRC and adenomatous polyps ${ }^{[96]}$. Chemically modified miR-143 (miR-143BP) has improved nuclease-resistance and may serve as RNA medicine for the treatment of $\mathrm{CRC}^{\left[{ }^{[9]}\right.}$. The level of miR-92 and miR-17-3p has been reported to be significantly higher in the plasma of colon cancer patients compared with healthy controls, and is suggested as potential markers for CRC. Stool miR-17-92 clusters and miR-135 are also significantly increased in CRC patients ${ }^{[98,99]}$. MiR-31 is up-regulated in CRC, and suppression of miR-31 may increase sensitivity to 5-FU and inhibit cell migration and invasion ${ }^{[100-103]}$. Plasma miR-141 is reported to be a novel biomarker in detecting metastatic colon cancer, and high level in plasma is associated with poor prognosis of CRC ${ }^{[104]}$. In stage II colon cancer, high level of miR-320 and/or miR-498 is correlated with progression-free survival ${ }^{[105]}$. MiR-21, miR-20a, and miR155 are also highly expressed in CRC. High level of miR-21 is associated with poor benefit from 5-FU adjuvant chemotherapy in CRC ${ }^{[106-108]}$, and miR-21 expression level was considered an independent predictor of colon cancer prognosis ${ }^{[109]}$.

Epigenetic regulation of miRNAs expression, including DNA methylation and histone deacetylation, was found in CRC. Frequent methylation of miR-9-1, miR-129-2, and miR-137 was observed in CRC but not in normal mucosa. Methylation of miR-9-1 was more frequent in advanced cancer and was significantly

\section{References}

[1] Gray R, Barnwell J , McConkey C, et al. Adjuvant chemotherapy versus observation in patients with colorectal cancer: a randomised study. Lancet, 2007, 370:2020 2029.

[2] Arnold CN, Goel A, Blum HE, et al. Molecular pathogenesis of colorectal cancer: implications for molecular diagnosis. Cancer, 2005, 104:2035-2047

[3] Grady WM, Carethers JM. Genomic and epigenetic instability in colorectal cancer pathogenesis. Gastroenterology, 2008,135: 1079-1099

[4] Markowitz SD, Bertagnolli MM. Molecular origins of cancer: associated with regional nodal invasion, vascular invasion, and metastasis. Expression of these miRNAs was restored after treatment with 5-aza-2'-deoxycytidine (AZA, a DNA methyltransferase inhibitor) and 4-phenylbutyric acid (PBA, a HDAC inhibitor) in CRC cell lines ${ }^{[110,111]}$. Loss of miR-127 expression was found in HCT116 cells, though expression could be restored by AZA and PBA in a dose-dependent manner ${ }^{[112]}$. MiR-124a expression was down-regulated by DNA methylation in HCT116 cells compared with DKO cells (double knockout of DNMT1 and DNMT3b in HCT116 cells) $)^{[113]}$.

\section{Conclusions}

Changes of DNA methylation may serve as diagnostic, prognostic, and chemosensitive markers in CRC. The reversibility of epigenetic changes makes it possible to treat CRC with DNA methyltransferase inhibitors and histone deacetylase inhibitors. However, the available demethylating agents are globally effective. It is great beneficial for cancer treatment to develop gene-specific demethylating approaches. MiRNAs expression patterns may associate with CRC, but further study is necessary to develop diagnostic and prognostic markers. The era is coming to apply epigenetic methods to CRC therapy.

\section{Acknowledgments}

This work was supported by grants from the National Basic Research Program (973 Program No. 2012CB934002, 2010CB912802), National Key Scientific instrument Special Programme of China (Grant No. 2011YQ03013405), and National Science Foundation of China (Grant No. 81121004, 81071953).

Received: 2011-06-09; revised: 2011-09-20; accepted: 2011-09-26.

molecular basis of colorectal cancer. N Engl J Med, 2009,361: 2449-2460.

[5] Egger G, Liang G, Aparicio A, et al. Epigenetics in human disease and prospects for epigenetic therapy. Nature, 2004,429:457-463.

[6] Issa JP, Garcia-Manero G, Giles FJ, et al. Phase 1 study of low-dose prolonged exposure schedules of the hypomethylating agent 5-aza-2'-deoxycytidine (decitabine) in hematopoietic malignancies. Blood, 2004,103:1635-1640.

[7] Jones PA, Takai D. The role of DNA methylation in mammalian epigenetics. Science, 2001,293: 1068-1070. 
[8] Csankovszki G, Nagy A, Jaenisch R. Synergism of Xist RNA, DNA methylation, and histone hypoacetylation in maintaining $X$ chromosome inactivation. J Cell Biol, 2001,153:773-784.

[9] Bird AP. CpG-rich islands and the function of DNA methylation. Nature, 1986,321:209-213.

[10] Bird A. DNA methylation patterns and epigenetic memory. Genes Dev, 2002,16:6-21.

[11] Laird PW. The power and the promise of DNA methylation markers. Nat Rev Cancer, 2003,3:253-266.

[12] Jair KW, Bachman KE, Suzuki H, et al. De novo CpG island methylation in human cancer cells. Cancer Res, 2006,66:682692.

[13] Copeland RA, Olhava EJ, Scott MP. Targeting epigenetic enzymes for drug discovery. Curr Opin Chem Biol, 2010,14: 505-510.

[14] Marks P, Rifkind RA, Richon VM, et al. Histone deacetylases and cancer: causes and therapies. Nat Rev Cancer, 2001,1: 194-202.

[15] Kaneda M, Okano M, Hata K, et al. Essential role for de novo DNA methyltransferase Dnmt3a in paternal and maternal imprinting. Nature, 2004,429:900-903.

[16] Chen ZX, Mann JR, Hsieh CL, et al. Physical and functional interactions between the human Dnmt3l protein and members of the de novo methyltransferase family. J Cell Biochem, 2005,95:902-917.

[17] Dong A, Yoder JA, Zhang X, et al. Structure of human dnmt2, an enigmatic DNA methyltransferase homolog that displays denaturant-resistant binding to DNA. Nucleic Acids Res, 2001,29:439-448.

[18] Free A, Wakefield RI, Smith BO, et al. DNA recognition by the methyl-CpG binding domain of MeCP2. J Biol Chem, 2001,276:3353-3360.

[19] Meehan RR, Lewis JD, Bird AP. Characterization of MeCP2, a vertebrate DNA binding protein with affinity for methylated DNA. Nucleic Acids Res, 1992,20:5085-5092.

[20] Sparmann A, van Lohuizen M. Polycomb silencers control cell fate, development and cancer. Nat Rev Cancer, 2006,6:846856

[21] Mai A. The therapeutic uses of chromatin-modifying agents. Expert Opin Ther Targets, 2007,11:835-851.

[22] Esteller M, Fraga MF, Guo M, et al. DNA methylation patterns in hereditary human cancers mimic sporadic tumorigenesis. Hum Mol Genet, 2001,10:3001-3007.

[23] Esteller M, Corn PG, Baylin SB, et al. A gene hypermethylation profile of human cancer. Cancer Res, 2001,61:3225-3229.

[24] Toyota M, Ahuja N, Ohe-Toyota M, et al. CpG island methylator phenotype in colorectal cancer. Proc Natl Acad Sci U S A, 1999,96:8681-8686.

[25] Shen L, Kondo Y, Rosner GL, et al. MGMT promoter methylation and field defect in sporadic colorectal cancer. J Natl Cancer Inst, 2005,97:1330-1338.

[26] Kawakami K, Ruszkiewicz A, Bennett G, et al. DNA hypermethylation in the normal colonic mucosa of patients with colorectal cancer. Br J Cancer, 2006,94:593-598.

[27] Menigatti M, Truninger K, Gebbers JO, et al. Normal colorectal mucosa exhibits sex- and segment-specific susceptibility to DNA methylation at the $\mathrm{hMIH1}$ and MGMT promoters. Oncogene, 2009,28:899-909.

[28] Esteller M. Epigenetics in cancer. N Engl J Med, 2008,358: 1148-1159

[29] Ahuja N, Li Q, Mohan AL, et al. Aging and DNA methylation in colorectal mucosa and cancer. Cancer Res, 1998,58:5489 5494.
[30] Riojas MA, Guo M, Glockner SC, et al. Methylation-induced silencing of ASC/TMS1, a pro-apoptotic gene, is a late-stage event in colorectal cancer. Cancer Biol Ther, 2007,6:1710 1716

[31] Zhang W, Glockner SC, Guo M, et al. Epigenetic inactivation of the canonical Wnt antagonist SRY-box containing gene 17 in colorectal cancer. Cancer Res, 2008,68:2764-2772.

[32] Lee BB, Lee EJ, Jung EH, et al. Aberrant methylation of APC, MGMT, RASSF2A, and WIf-1 genes in plasma as a biomarker for early detection of colorectal cancer. Clin Cancer Res, 2009, 15:6185-6191.

[33] Grady WM, Rajput A, Lutterbaugh JD, et al. Detection of aberrantly methylated $\mathrm{hMIH1}$ promoter DNA in the serum of patients with microsatellite unstable colon cancer. Cancer Res, 2001,61:900-902.

[34] Zou HZ, Yu BM, Wang ZW, et al. Detection of aberrant p16 methylation in the serum of colorectal cancer patients. Clin Cancer Res, 2002,8:188-191.

[35] Nakayama H, Hibi K, Taguchi M, et al. Molecular detection of p16 promoter methylation in the serum of colorectal cancer patients. Cancer Lett, 2002,188:115-119

[36] Yamaguchi S, Asao T, Nakamura J, et al. High frequency of DAP-kinase gene promoter methylation in colorectal cancer specimens and its identification in serum. Cancer Lett, 2003,194:99-105.

[37] Fearon ER, Vogelstein B. A genetic model for colorectal tumorigenesis. Cell, 1990,61:759-767.

[38] Kambara T, Simms LA, Whitehall VL, et al. BRAF mutation is associated with DNA methylation in serrated polyps and cancers of the colorectum. Gut, 2004,53:1137-1144

[39] Boland CR, Goel A. Microsatellite instability in colorectal cancer. Gastroenterology, 2010,138:2073-2087.

[40] Issa JP. CpG island methylator phenotype in cancer. Nat Rev Cancer, 2004,4:988-993.

[41] Kim MS, Lee J, Sidransky D. DNA methylation markers in colorectal cancer. Cancer Metastasis Rev, 2010,29:181206.

[42] Feinberg AP, Vogelstein B. Hypomethylation distinguishes genes of some human cancers from their normal counterparts. Nature, 1983,301:89-92.

[43] Hibi K, Goto T, Mizukami H, et al. Demethylation of the $\mathrm{CDH} 3$ gene is frequently detected in advanced colorectal cancer. Anticancer Res, 2009,29:2215-2217.

[44] Braakhuis BJ, Tabor MP, Kummer JA, et al. A genetic explanation of slaughter's concept of field cancerization: evidence and clinical implications. Cancer Res, 2003,63:17271730

[45] Guo M, House MG, Hooker C, et al. Promoter hypermethylation of resected bronchial margins: a field defect of changes? Clin Cancer Res, 2004, 10:5131-5136

[46] Rainier S, Johnson LA, Dobry CJ, et al. Relaxation of imprinted genes in human cancer. Nature, 1993,362:747-749.

[47] Ogawa O, Eccles MR, Szeto J, et al. Relaxation of insulin-like growth factor II gene imprinting implicated in Wilms' tumour. Nature, 1993,362:749-751.

[48] Cui H, Horon IL, Ohlsson R, et al. Loss of imprinting in normal tissue of colorectal cancer patients with microsatellite instability. Nat Med, 1998,4:1276-1280.

[49] Feinberg AP, Tycko B. The history of cancer epigenetics. Nat Rev Cancer, 2004,4:143-153.

[50] Cui H, Cruz-Correa M, Giardiello FM, et al. Loss of IGF2 imprinting: a potential marker of colorectal cancer risk. Science, 2003,299:1753-1755. 
[51] McMichael AJ. Food, nutrition, physical activity and cancer prevention. Authoritative report from World Cancer Research Fund provides global update. Public Health Nutr, 2008,11:762763

[52] Shaw S, Jayatilleke E, Herbert V, et al. Cleavage of folates during ethanol metabolism. Role of acetaldehyde/xanthine oxidase-generated superoxide. Biochem J, 1989,257:277 280.

[53] Romero JJ, Tamura T, Halsted $\mathrm{CH}$. Intestinal absorption of $[3 \mathrm{H}]$ folic acid in the chronic alcoholic monkey. Gastroenterology, 1981,80:99-102.

[54] Eichner ER, Hillman RS. The evolution of anemia in alcoholic patients. Am J Med, 1971,50:218-232.

[55] Pedersen A, Johansen C, Gronbaek M. Relations between amount and type of alcohol and colon and rectal cancer in a danish population based cohort study. Gut, 2003,52:861 867.

[56] Stemmermann GN, Nomura AM, Chyou PH, et al. Prospective study of alcohol intake and large bowel cancer. Dig Dis Sci, 1990,35:1414-1420

[57] Kim YI. Folate and colorectal cancer: an evidence-based critical review. Mol Nutr Food Res, 2007,51:267-292.

[58] Sanjoaquin MA, Allen N, Couto E, et al. Folate intake and colorectal cancer risk: a meta-analytical approach. Int Cancer, 2005,113:825-828.

[59] James SJ, Pogribny IP, Pogribna M, et al. Mechanisms of DNA damage, DNA hypomethylation, and tumor progression in the folate/methyl-deficient rat model of hepatocarcinogenesis. J Nutr, 2003, 133:3740S-3747S.

[60] Berger SL. Histone modifications in transcriptional regulation. Curr Opin Genet Dev, 2002,12:142-148.

[61] Barski A, Cuddapah S, Cui K, et al. High-resolution profiling of histone methylations in the human genome. Cell, 2007,129: 823-837.

[62] Litt MD, Simpson M, Gaszner M, et al. Correlation between histone lysine methylation and developmental changes at the chicken beta-globin locus. Science, 2001,293:2453 2455.

[63] Noma K, Allis CD, Grewal SI. Transitions in distinct histone $\mathrm{H3}$ methylation patterns at the heterochromatin domain boundaries. Science, 2001,293:1150-1155.

[64] Peters AH, Mermoud JE, O'Carroll D, et al. Histone H3 lysine 9 methylation is an epigenetic imprint of facultative heterochromatin. Nat Genet, 2002,30:77-80.

[65] Fraga MF, Ballestar E, Villar-Garea A, et al. Loss of acetylation at Lys 16 and trimethylation at Lys20 of histone $\mathrm{H} 4$ is a common hallmark of human cancer. Nat Genet, 2005,37:391 400.

[66] Seligson DB, Horvath S, Shi T, et al. Global histone modification patterns predict risk of prostate cancer recurrence. Nature, 2005,435:1262-1266.

[67] Richon VM, Sandhoff TW, Rifkind RA, et al. Histone deacetylase inhibitor selectively induces p21WAF1 expression and gene-associated histone acetylation. Proc Natl Acad Sci U S A, 2000,97:10014-10019.

[68] Pruitt K, Zinn RL, Ohm JE, et al. Inhibition of SIRT1 reactivates silenced cancer genes without loss of promoter DNA hypermethylation. PLoS Genet, 2006,2:e40.

[69] Tsang DPF, Cheng ASL. Epigenetic regulation of signaling pathways in cancer: role of the histone methyltransferase EZH2. J Gastroenterol Hepatol, 2011,26:19-27.

[70] Pelaez IM, Kalogeropoulou M, Ferraro A, et al. Oncogenic ras alters the global and gene-specific histone modification pattern during epithelial-mesenchymal transition in colorectal carcinoma cells. Int J Biochem Cell Biol, 2010,42:911-920.

71] Baylin SB, Herman JG. DNA hypermethylation in tumorigenesis: epigenetics joins genetics. Trends Genet, 2000,16(4):168-174

[72] Jones PA, Laird PW. Cancer epigenetics comes of age. Nat Genet, 1999,21:163-167.

[73] Jenuwein T, Allis CD. Translating the histone code. Science, 2001,293: 1074-1080

[74] Tamaru H, Selker EU. A histone H3 methyltransferase controls DNA methylation in neurospora crassa. Nature, 2001,414:277283.

[75] Jackson JP, Lindroth AM, Cao X, et al. Control of cpnpg DNA methylation by the kryptonite histone $\mathrm{H} 3$ methyltransferase. Nature, 2002,416:556-560.

[76] Herman JG, Umar A, Polyak K, et al. Incidence and functional consequences of $\mathrm{HMLH1}$ promoter hypermethylation in colorectal carcinoma. Proc Natl Acad Sci U S A, 1998,95: 6870-6875

[77] Fahrner JA, Eguchi S, Herman JG, et al. Dependence of histone modifications and gene expression on DNA hypermethylation in cancer. Cancer Res, 2002,62:72137218

[78] Wilson AJ, Byun DS, Popova N, et al. Histone deacetylase 3 (HDAC3) and other class I HDACS regulate colon cell maturation and p21 expression and are deregulated in human colon cancer. J Biol Chem, 2006,281:13548-13558.

[79] Ishihama K, Yamakawa M, Semba S, et al. Expression of HDAC1 and CBP/p300 in human colorectal carcinomas. J Clin Pathol, 2007,60:1205-1210.

[80] Zhu P, Martin E, Mengwasser J, et al. Induction of HDAC2 expression upon loss of APC in colorectal tumorigenesis. Cancer Cell, 2004,5:455-463.

[81] Brehm A, Miska EA, McCance DJ, et al. Retinoblastoma protein recruits histone deacetylase to repress transcription. Nature, 1998,391:597-601

[82] Magnaghi-Jaulin L, Groisman R, Naguibneva I, et al. Retinoblastoma protein represses transcription by recruiting a histone deacetylase. Nature, 1998,391:601-605.

[83] DePinho RA. Transcriptional repression. The cancer-chromatin connection. Nature, 1998,391:533, 535-536.

[84] Kim YS, Tsao D, Siddiqui B, et al. Effects of sodium butyrate and dimethylsulfoxide on biochemical properties of human colon cancer cells. Cancer, 1980,45:1185-1192.

[85] Dashwood $\mathrm{RH}$, Ho E. Dietary histone deacetylase inhibitors: from cells to mice to man. Semin Cancer Biol, 2007,17:363369.

[86] Yoshida M, Kijima M, Akita M, et al. Potent and specific inhibition of mammalian histone deacetylase both in vivo and in vitro by trichostatin a. J Biol Chem, 1990,265:17174 17179

[87] Richon VM, Emiliani S, Verdin E, et al. A class of hybrid polar inducers of transformed cell differentiation inhibits histone deacetylases. Proc Natl Acad Sci U S A, 1998,95:30033007

[88] Myzak MC, Ho E, Dashwood RH. Dietary agents as histone deacetylase inhibitors. Mol Carcinog, 2006,45:443-446.

[89] Rasheed WK, Johnstone RW, Prince HM. Histone deacetylase inhibitors in cancer therapy. Expert Opin Investig Drugs, 2007, 16:659-678.

[90] Mack GS. Epigenetic cancer therapy makes headway. J Natl Cancer Inst, 2006,98:1443-1444.

[91] Muller $\mathrm{Cl}$, Ruter B, Koeffler HP, et al. DNA hypermethylation of myeloid cells, a novel therapeutic target in MDS and AML. 
Curr Pharm Biotechnol, 2006,7:315-321.

[92] Lee $\mathrm{Y}$, Ahn C, Han J, et al. The nuclear RNase III Drosha initiates microRNA processing. Nature, 2003,425:415-419.

[93] Lund E, Guttinger S, Calado A, et al. Nuclear export of microrna precursors. Science, 2004,303:95-98.

[94] Nilsen TW. Mechanisms of microRNA-mediated gene regulation in animal cells. Trends Genet, 2007,23:243-249.

[95] Wiemer EA. The role of microRNAs in cancer: no small matter. Eur J Cancer, 2007,43:1529-1544.

[96] Michael MZ, SM OC, van Holst Pellekaan NG, et al. Reduced accumulation of specific microRNAs in colorectal neoplasia. Mol Cancer Res, 2003,1:882-891.

[97] Kitade $Y$, Akao Y. MicroRNAs and their therapeutic potential for human diseases: microRNAs, miR-143 and -145 , function as anti-oncomirs and the application of chemically modified miR143 as an anti-cancer drug. J Pharmacol Sci, 2010,114:276280.

[98] $\mathrm{Ng}$ EK, Chong WW, Jin $\mathrm{H}$, et al. Differential expression of microRNAs in plasma of patients with colorectal cancer: a potential marker for colorectal cancer screening. Gut, 2009,58: 1375-1381.

[99] Koga Y, Yasunaga M, Takahashi A, et al. MicroRNA expression profiling of exfoliated colonocytes isolated from feces for colorectal cancer screening. Cancer Prev Res (Phila), 2010,3 $1435-1442$.

[100] Lagos-Quintana M, Rauhut R, Lendeckel W, et al. Identification of novel genes coding for small expressed RNAs. Science, 2001,294:853-858.

[101] Wang CJ, Zhou ZG, Wang L, et al. Clinicopathological significance of microRNA-31, -143 and -145 expression in colorectal cancer. Dis Markers, 2009,26:27-34.

[102] Slaby O, Svoboda M, Fabian P, et al. Altered expression of miR-21, miR-31, miR-143 and miR-145 is related to clinicopathologic features of colorectal cancer. Oncology, 2007,72:397-402.

[103] Wang CJ, Stratmann J, Zhou ZG, et al. Suppression of microRNA-31 increases sensitivity to 5-FU at an early stage, and affects cell migration and invasion in HCT-116 colon cancer cells. BMC Cancer, 2010,10:616.

[104] Cheng H, Zhang L, Cogdell DE, et al. Circulating plasma miR141 is a novel biomarker for metastatic colon cancer and predicts poor prognosis. PLoS One, 2011,6:e17745.

[105] Schepeler T, Reinert JT, Ostenfeld MS, et al. Diagnostic and prognostic micrornas in stage II colon cancer. Cancer Res, 2008,68:6416-6424

[106] Schetter AJ, Leung SY, Sohn JJ, et al. MicroRNA expression profiles associated with prognosis and therapeutic outcome in colon adenocarcinoma. JAMA, 2008,299:425-436.

[107] Volinia S, Calin GA, Liu CG, et al. A microRNA expression signature of human solid tumors defines cancer gene targets. Proc Natl Acad Sci U S A, 2006,103:2257-2261.

[108] Longley DB, Harkin DP, Johnston PG. 5-fluorouracil: mechanisms of action and clinical strategies. Nat Rev Cancer, 2003,3:330-338.

[109] Schetter AJ, Nguyen GH, Bowman ED, et al. Association of inflammation-related and microRNA gene expression with cancer-specific mortality of colon adenocarcinoma. Clin Cancer Res, 2009, 15:5878-5887.

[110] Bandres E, Agirre X, Bitarte N, et al. Epigenetic regulation of microRNA expression in colorectal cancer. Int $\mathrm{J}$ Cancer, 2009, 125:2737-2743

[111] Balaguer F, Link A, Lozano JJ, et al. Epigenetic silencing of miR-137 is an early event in colorectal carcinogenesis. Cancer
Res, 2010,70:6609-6618

[112] Saito $Y$, Liang G, Egger $G$, et al. Specific activation of microRNA-127 with downregulation of the proto-oncogene BCL6 by chromatin-modifying drugs in human cancer cells. Cancer Cell, 2006,9:435-443.

[113] Lujambio A, Ropero S, Ballestar E, et al. Genetic unmasking of an epigenetically silenced microrna in human cancer cells. Cancer Res, 2007,67:1424-1429.

[114] Wang Z, Yuan X, Jiao N, et al. $\mathrm{CDH}_{13}$ and FIBN3 gene methylation are associated with poor prognosis in colorectal cancer. Pathol Oncol Res, 2012, 18:263-270.

[115] Mitomi H, Fukui N, Tanaka N, et al. Aberrant p16 ((INK4a)) methylation is a frequent event in colorectal cancers: prognostic value and relation to mRNA expression and immunoreactivity. J Cancer Res Clin Oncol, 2010,136:323331.

[116] Pancione M, Sabatino L, Fucci A, et al. Epigenetic silencing of peroxisome proliferator-activated receptor gamma is a biomarker for colorectal cancer progression and adverse patients' outcome. PLoS One, 2010,5:e14229.

[117] Herath NI, Doecke J, Spanevello MD, et al. Epigenetic silencing of EphA1 expression in colorectal cancer is correlated with poor survival. Br J Cancer, 2009,100:1095-1102.

[118] Rawson JB, Manno M, Mrkonjic M, et al. Promoter methylation of Wnt antagonists DKK1 and SFRP1 is associated with opposing tumor subtypes in two large populations of colorectal cancer patients. Carcinogenesis, 2011,32:741-747.

[119] Kim JC, Lee HC, Cho DH, et al. Genome-wide identification of possible methylation markers chemosensitive to targeted regimens in colorectal cancers. J Cancer Res Clin Oncol, 2011,137:1571-1580.

[120] Harder J, Engelstaedter V, Usadel H, et al. CpG-island methylation of the ER promoter in colorectal cancer: analysis of micrometastases in lymph nodes from UICC stage I and II patients. Br J Cancer, 2009, 100:360-365.

[121] Brandes JC, van Engeland M, Wouters KA, et al. CHFR promoter hypermethylation in colon cancer correlates with the microsatellite instability phenotype. Carcinogenesis, 2005,26: 1152-1156.

[122] Kim MS, Louwagie J, Carvalho B, et al. Promoter DNA methylation of oncostatin $\mathrm{m}$ receptor-beta as a novel diagnostic and therapeutic marker in colon cancer. PLoS One, 2009,4: e6555.

[123] Huang Z, Li L, Wang J. Hypermethylation of SFRP2 as a potential marker for stool-based detection of colorectal cancer and precancerous lesions. Dig Dis Sci, 2007,52:22872291

[124] Oberwalder M, Zitt M, Wontner C, et al. SFRP2 methylation in fecal DNA - a marker for colorectal polyps. Int J Colorectal Dis, 2008,23:15-19.

[125] Mittag F, Kuester D, Vieth M, et al. DAPK promotor methylation is an early event in colorectal carcinogenesis. Cancer Lett, 2006,240:69-75.

[126] Glockner SC, Dhir M, Yi JM, et al. Methylation of TFPI2 in stool DNA: a potential novel biomarker for the detection of colorectal cancer. Cancer Res, 2009,69:4691-4699.

[127] Hellebrekers DM, Lentjes MH, van den Bosch SM, et al. GATA4 and GATA5 are potential tumor suppressors and biomarkers in colorectal cancer. Clin Cancer Res, 2009,15: 3990-3997.

[128] Liu $M$, Peng $Y$, Wang $X$, et al. NGX6 gene mediated by promoter methylation as a potential molecular marker in colorectal cancer. BMC Cancer, 2010,10:160. 
[129] Miotto E, Sabbioni S, Veronese A, et al. Frequent aberrant methylation of the $\mathrm{CDH} 4$ gene promoter in human colorectal and gastric cancer. Cancer Res, 2004,64:8156-8159.

[130 ] Ishiguro A, Takahata T, Saito M, et al. Influence of methylated p15 and p16 genes on clinicopathological features in colorectal cancer. J Gastroenterol Hepatol, 2006,21:1334 1339.
Submit your next manuscript to Chinese Journal of Cancer and take full advantage of:

- Open access

- No charge to authors

- Quickly published

- Thorough peer review

- Professionally edited

- No space constraints

- Indexed by PubMed, CA, and Google Scholar

Submit your manuscript at www.cjcsysu.com 